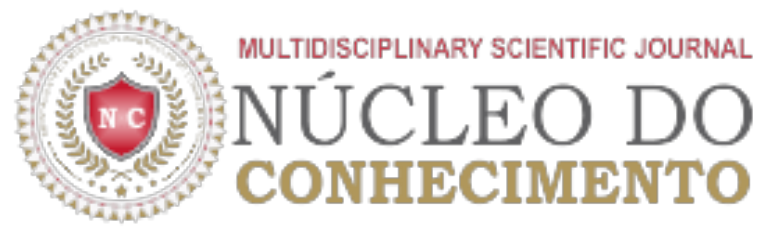

\section{BRICS: Desafios e Oportunidades para o Agronegócio Brasileiro}

\author{
FERNANDES, Alessandro [1], ALMEIDA, Siderly do Carmo Dahle de [2]
}

FERNANDES, Alessandro; ALMEIDA, Siderly do Carmo Dahle de. BRICS: Desafios e Oportunidades para o Agronegócio Brasileiro. Revista Científica Multidisciplinar Núcleo do Conhecimento. Edição 04. Ano 02, Vol. 01. pp 405-420, Julho de 2017. ISSN:2448-0959

\section{RESUMO}

O trabalho apresenta um estudo realizado com o objetivo de analisar o mercado potencial aberto para o agronegócio brasileiro com a consolidação do bloco BRICS [3]. A pesquisa é de natureza descritiva, predominantemente quantitativa. Frente a configuração do bloco, optamos por analisar os dados das relações bilaterais do Brasil com cada um dos países integrantes, uma vez que o estudo demonstrou que esta é a forma de relação predominante entre os países membros. Os resultados apresentados demonstram o potencial do mercado analisado para o comércio exterior dos produtos e serviços ligados a atividade agropecuária, mas também os desafios que o país deverá superar para o êxito econômico.

Palavras-Chaves: Agronegócio, BRICS, China, Commodities, Rússia.

\section{INTRODUÇÃO}

A consolidação do bloco econômico BRICS alterou a participação do Brasil no mercado externo, com o fortalecimento das relações negociais e a possibilidade de cooperação tecnológica entre os países membros, outorgando-o uma posição de raro protagonismo internacional.

Diante desta inédita situação, é relevante a análise das oportunidades e os desafios que se apresentam para o agronegócio brasileiro nessa nossa conjuntura, unindo nova vocação agropecuária com um promissor mercado consumidor.

O presente trabalho pretende desenvolver este estudo, aprofundando as relações negociais para o agronegócio brasileiro com os países do BRICS, priorizando a análise dos desafios e oportunidades para incremento das exportações brasileiras, discutindo o mercado potencial para o produtos e serviços vinculados ao agronegócio neste bloco de países e a forma como ocorrem as relações comerciais entre eles, buscando trabalhar as oportunidades que estimulariam a exportação de produtos e serviços do 
agronegócio brasileiro para estes países e diagnosticando os desafios que os envolvidos nesta cadeia precisam superar para não perderem mercado para os demais países membros.

Para tanto, inicialmente buscou-se conceituar a organização do BRICS, desde seu surgimento até a evolução, que culminou com a entrada da África do Sul. Estudamos ainda sua (des)organização institucional.

Em um segundo momento o presente texto se dispôs a analisar as relações comerciais mais relevantes desenvolvidas entre os países integrantes do bloco.

O presente estudo não se debruçará sobre as possibilidades de investimentos em infraestrutura financiados pelo Novo Banco de Desenvolvimento (NBD), que poderiam minimizar gargalos logísticos que prejudicam a competitividade de nossos produtos, uma vez que o referido banco somente deve ter sua atividade regulamentada na $7^{\text {a }}$ Cúpula do BRICS, na cidade Russa de Ufá, programada para o mês de julho de 2015, data em que já se encontrava finalizada a redação do desenvolvimento do trabalho.

\section{BRICS}

O acrônimo BRICs (originalmente com s minúsculo) foi idealizada por Jim O’Neill (2001) em um estudo da Goldman Sachs[4] referindo-se ao conjunto dos quatro maiores países emergentes - Brasil, Rússia, Índia e China - que deverão representar em 2050, segundo o estudo, uma fatia maior da economia mundial do que os atuais países ricos. A sigla BRIC ainda faz um trocadilho com Brick, remetendo foneticamente a palavra tijolo em inglês, numa alusão a construção de uma nova arquitetura mundial. No entender de Jim O'Neill (2001), dois componentes identificavam e aproximavam os BRICs: dimensão da economia e taxas de crescimento.

A sigla surgiu da intenção da Goldman Sachs, uma casa bancária, de despertar o interesse de seus clientes. Criar o acrônimo era uma solução rápida e eficaz para lembrar onde estariam, em médio e longo prazos, boas oportunidades (FONSECA JÚNIOR, 2012).

Cozendey (2012, p.107) descreve de forma clara a intenção dessa instituição com essa nova definição:

Era para ser uma definição de carteira de investimentos. Era para ser um instrumento de marketing financeiro em um ambiente de instrumentos financeiros crescentemente mirabolantes. Era para ser um chamariz para investidores em busca de risco. Ainda assim, como a semente que cai em chão fértil, o acrônimo BRIC germinou e lançou rapidamente seus ramos para além do mundo das finanças. Antes mesmo que os países integrantes do BRIC decidissem realizar reuniões de cúpula anuais, já fervilhavam discussões entre os analistas sobre se tal ou qual país era mesmo um membro do BRIC em comparação com os outros, se possuíam uma identidade mínima comum, que papel lhes caberia na evolução da ordem internacional.

Por óbvio, a consolidação de um grupo tão heterogêneo não se dará sem sobressaltos, como explicitado abaixo por Barbosa (2009, p. 100):

Brasil é o único país que tem uma relação político-diplomático e econômico-comercial fluida com todos os membros do BRIC. Razões históricas ainda tornam cautelosa a aproximação entre a Rússia, a China e 
a Índia. A construção de um clima de confiança entre eles é um processo demorado, que será testado de tempos em tempos. A participação em um mesmo grupo pode ajudar a alterar gradualmente essa situação.

Assim, de forma artificial, foram criadas as condições para a aproximação de países tão distantes, tanto geograficamente como culturalmente.

\subsection{INCLUSÃO DA ÁFRICA DO SUL}

Após convite dos integrantes do grupo, em especial da China, a África do Sul foi admitida como uma nação do BRICs em 24 de dezembro de 2010 na Reunião de Chanceleres do foro, mas o ingresso oficial somente se deu na Terceira Cúpula do BRICs, realizada em Sanya, na China, em 14 de abril de 2011. A letra "S" em BRICS, após essa inclusão gravada em maiúscula, representa a África do Sul, em sua grafia em inglês, South Africa.

O "pai” do BRICs, Jim O'Neill, já presidente da Goldman Sachs Asset Management, expressou surpresa com essa adesão ao "bloco" declarando que a África do Sul "is nowhere near constituting a BRIC", sugerindo ainda que a Nigéria, incluída em seu novo portfólio promocional[5], teria maiores condições para o ingresso, considerando os critérios utilizados para agrupar originalmente os quatro países em seu acrônimo (SPECTOR, 2011). Em contrapartida, Martyn Davies, um perito no mercado emergente sulafricano, entende que a decisão de convidar a África do Sul faz pouco sentido comercial, mas foi politicamente astuta, dadas as tentativas da China em estabelecer uma presença na África (SMITH, 2011).

Analisar a inclusão da África do Sul com os mesmos critérios utilizados para identificar os países no grupo BRIC, dimensão da economia e taxas de crescimento, não é suficiente, sendo que nessa análise a Nigéria realmente constitui-se em uma porta de acesso mais lógica para o mercado africano. Inegavelmente a África do Sul não possui atributos econômicos similares aos dos demais países do BRIC, mas pesou a experiência democrática (para padrões africanos e, por que não, russos e chineses) e a lembrança histórica da vitória sobre o Apartheid. Pfeizer $(2012$, p.80) trabalha de forma clara a opção pela África do Sul no texto colacionado abaixo.

A República da África do Sul, ao juntar-se aos BRICS, a partir de 2010, dota-lhes da representatividade emanada de um país que provém de um continente de um bilhão de pessoas em franca expansão de seus mercados domésticos e de sua capacidade de extração de recursos naturais. Traz à baila ainda o êxito de um experimento político que logrou desenhar um pacto social no qual pobres e ricos das mais variadas etnias compartilham um espaço de oportunidades para a prosperidade e a paz individuais. Assim, a adição sul-africana contraria o elemento seminal dos BRICS, qual seja, a pujança econômica do país-membro; sua contribuição dá-se, sim, pelo elemento político democrático ao fornecer um exemplo, mesmo que incompleto e imperfeito, de saída virtuosa de uma crise social complexa - exatamente a fórmula que se busca hoje no e para o mundo.

A entrada da África do Sul no grupo provocou discussões sobre quem mais poderia aderir ao bloco com o tempo, aumentando o seu capital político. Fala-se da Turquia, a quem a alternativa de ingresso na União Europeia parece definitivamente fechada e que, a exemplo dos demais integrantes dos BRICS, tem ostensivamente se esforçado para transcender sua posição de potência regional. Coreia do Sul, Indonésia e México são considerados outros possíveis “candidatos" (LINS E SILVA, 2012). Até uma aproximação com a Grécia, por intermédio do recente Banco de Investimentos do BRICS foi aventada (SÁNCHEZ- 
VALLEJO, 2015). Na lição de Barbosa (2012), a ampliação do número de países membros deveria ser combatido pelo Brasil, pois isso diluiria o peso do grupo e o seu próprio papel no bloco.

Segundos dados de Silva (2013), os países dos BRICS representam 43,03\% da população mundial, $18 \%$ do Produto Interno Bruto (PIB) nominal mundial (25\% do PIB per capita), 25,91\% da área terrestre do planeta e 46,3\% do crescimento econômico global de 2000 a 2008.

\subsection{ORGANIZAÇÃO DO BLOCO}

O BRICS não é hoje um bloco político econômico como o MERCOSUL ou a União Europeia, tampouco militar como a OTAN ou o extinto Pacto de Varsóvia. Não se constitui em zona de preferência tarifária, zona de livre comércio, não tem união econômica, monetária ou aduaneira e sua cooperação desenvolvese mais através de relações bilaterais do que multilaterais (JONATHAS, 2014).

Frente ao estágio ainda inicial de organização do grupo hoje é mais fácil definir o grupo citando suas diferenças com outros blocos que o caracterizando, afinal trata-se de cooperação entre países sem proximidade geográfica ou cultural, com status apenas de bloco semi-institucionalizado.

A respeito da evolução para bloco econômico, o Embaixador Rubens Barbosa (2012, p. 182) descreve a opinião de Clovis Rossi, de que nada indica que esses países passem a ter interesses comuns a ponto de criar um bloco. Não haveria outra cola entre eles que não sejam territórios e populações gigantescas, fatores preexistentes à sigla BRIC.

A impossibilidade aparente de concordância entre os membros dos BRICS sobre temas vitais ao mesmo tempo fragiliza e fortalece o bloco (LINS E SILVA, 2012). O então presidente russo Medvedev, em 2009, afirmou que "O BRIC apresenta um formato muito interessante para debater temas globais, mas não é uma plataforma para tomada de decisões" (BARBOSA, 2009, p. 100).

O conceito abaixo, apesar de conter mais informações sobre o que o BRICS ainda não se constitui, é bastante claro sobre seu estágio atual de organização.

Os BRICS constituem, hoje, uma associação informal e estão longe de constituir um organismo multilateral (minilateral, para ser mais preciso). Não têm secretariado nem produzem binding decisions, mas têm um tipo de presença internacional que se bifurca à maneira de organismo multilateral. (FONSECA JÚNIOR, 2012, p. 17).

Natural essa indefinição quanto a organização do grupo, afinal este originou-se de forma artificial, por obra do marketing financeiro da Goldman Sachs.

Grupos ou organizações, em geral, são formados por Estados, a partir de interesses comuns, laços históricos, culturais ou geográficos. No caso do BRIC, a iniciativa conceitual partiu de um economista do Goldman Sachs, que, em 2001, produziu um trabalho, pensando no grande mercado que eles poderiam representar para seus clientes no futuro. (BARBOSA, 2012, p.176).

Os objetivos dos países integrantes dos blocos são tão impares quando suas peculiaridades. Cukier (2014) abordou essas divergências entre os objetivos dos países membros no trecho colacionado abaixo: 
O bloco serve muito mais os interesses particulares de cada país do que uma verdadeira coalizão de emergentes aonde os interesses coletivos são evidentes e comuns. A maioria das áreas de convergência recai sobre a vontade de contrapor a Europa e os EUA. Talvez um dos poucos beneficiários dessa convergência seja a África. Todos os países têm laços comerciais fortes com o continente e até mesmo a Rússia (o menos presente) tem aumentado seus investimentos em energia na região.

Apesar das frequentes reuniões de Cúpula, com a definição de calendário anual de reuniões, pode se afirmar que o BRICS avançou pouco institucionalmente, mantendo-se muito mais como um acrônimo comercial do que um bloco institucional. Inclusive o governo brasileiro entende que esta é a melhor estratégia negocial em oposição a de criação de uma área de livre-comércio entre tais países. Na visão brasileira, o mais adequado para os membros do BRICS é a adoção de uma estratégia baseada no aumento da compreensão mútua dos respectivos mercados, a fim de melhorar o mercado intrabloco (BECARD; BARROS-PLATIAU; OLIVEIRA, 2015).

\section{RELAÇÕES COMERCIAIS INTRABLOCO}

Com a ausência da institucionalização do bloco a aproximação comercial entre os países integrantes se dá principalmente através da formalização de acordos bilaterais, facilitados pelas frequentes reuniões e contatos entre as burocracias. Essa maior intimidade pode ser explorada em áreas de interesse brasileiro (BARBOSA, 2012). Esses acordos constituem-se em uma grande, se não a maior, oportunidade negocial da participação do Brasil com o BRICS, aproveitando para estabelecer negociações comerciais proveitosas, conforme pode se perceber no texto colacionado abaixo:

O papel dos BRICs no comércio mundial também está aumentando mais rápido que o comercio mundial como um todo. O comércio entre os BRICs acelerou sensivelmente, em especial, porque o Brasil e a Rússia fornecem boa parte das commodities necessárias à China e a Índia. Tal padrão sem dúvidas continuará nas próximas décadas, forçando ajustes na política de comércio exterior desses países (O’NEILL, 2012, p.52).

Essa aproximação tem possibilitado um crescimento gradativo da participação destes mercados na composição da pauta de exportações brasileiras, tornando-os desde 2011 o principal mercado de destino do comércio externo brasileiro, superando a União Europeia, totalizando 21,7\% do volume, concentrados principalmente em commodities agrícolas e minerais (POMERANZ, 2012). O volume de produtos agrícolas negociado entre os países do BRICS teve um incremento de 12\% durante os anos de 2010-2013, passando de USD 40 bilhões para USD 64 bilhões (ABREU, 2015).

Vamos analisar a seguir as relações bilaterais de comercio entre o Brasil e cada um dos demais integrantes do bloco. Os dados informados, sempre que não conste outra referência, foram coletados no informe do IPEA n ${ }^{\circ} 86$ (BRASIL, 2011).

\subsection{BRASIL - RÚSSIA}

As relações bilaterais do Brasil com a Rússia ainda se encontram em níveis baixos, passando de menos de USD 1 bilhão em 2000 para USD 6 bilhões em 2010, mas aumentando num ritmo quase duas vezes maior que o comércio brasileiro com o resto do mundo. A Rússia não representa papel destacado no ranking de exportações brasileiras, oscilando entre a $14^{\mathrm{a}}$ e $10^{\mathrm{a}}$ colocação, enquanto que como origem das 
importações sua posição é ainda menos relevante, mantendo-se em torno da $20^{a}$ colocação. Entretanto nota-se uma elevada concentração da pauta de exportações em produtos vinculados ao agronegócio, como carne e açúcar, representando $83 \%$ do total de exportações brasileiras. Situação semelhante é verificada na agenda de importações, onde a aquisição de fertilizantes responde por $60 \%$ do volume negociado.

A Rússia norteia sua política de compras externas por um sistema de cotas, estabelecidas em um momento em que o Brasil não tinha grande participação no mercado russo, mantendo-o prejudicado. $\mathrm{O}$ mercado de carnes russos foi abastecido, no período pós-Guerra Fria, em sua grande maioria por produtores americanos (TAVARES, 2014). Essa situação foi abalada pelo confronto da Rússia com a Ucrânia pelo controle da região da Criméia.

Em resposta a imposição de sanções contra a Rússia por parte dos Estados Unidos e União Europeia, o Kremlim emitiu proibição, por período não inferior a um ano[6], para importação de alimentos desses países, atingindo também as exportações da Austrália, do Canadá e da Noruega, e poderá ser estendida, como afirmou o Presidente Vladimir Putin, a "todos os países que decidiram impor sanções econômicas a entidades e/ou indivíduos russos, ou que se tenham associado a elas" (SANTAYANA, 2014).

Coincidentemente esse embate aconteceu num momento de intensas negociações entre os governos do Brasil e da Rússia no setor de carnes, e apenas três semanas após visita do presidente russo, Vladimir Putin, à Brasília (SAMORA, 2014), possibilitando a ampliação deste vasto mercado para produtores brasileiros de carne bovina, peixes, mariscos, frutas, legumes, verduras, carne de frango, leite e derivados.

Como consequência da medida, o número de unidades brasileiras habilitadas a exportar aos russos carnes bovina, suína e de aves mais do que triplicou de um dia para o outro, totalizando 139 plantas (SAMORA, 2014). A importância do mercado russo de carnes pode ser notada na declaração de Antônio Camardeli, presidente da Associação Brasileira dos Exportadores de Carne (ABIEC) "a Rússia é o melhor parceiro do Brasil. É país que compra e paga, e quem compra e paga tem preferência” (TAVARES, 2014). Segundo a ABIEC o Brasil exporta hoje para Rússia o equivalente a quarenta carretas por dia. A Rússia foi o segundo maior importador de carne bovina do Brasil em 2014 e o maior comprador de carne suína brasileira (PERES, 2015).

Além do mercado de proteína animal outro mercado em que se vislumbra oportunidades negociais para o Brasil é o de café. Em 1998 o consumo per capita de café solúvel era de 400 gramas. Esse consumo já era de 900 gramas em 2009, totalizando um consumo de 115 toneladas (TAVARES, 2014). Hoje o Brasil já ocupa o posto de segundo maior exportador, com $23 \%$ do volume exportado, inferior somente ao Vietnã, com 30,4\% (KAKHÉLINA, 2012).

\subsection{BRASIL - INDIA}

Os problemas regionais são mais relevantes que os desafios internacionais para a Índia, impedindo que considerem o BRICS como algo relevante. O equilíbrio com a China dentro do bloco é tênue frente a crescente rivalidade entre ambos países pela liderança regional junto ao Oceano Índico. Por isso, os indianos tendem a se manter ocupados e o bloco, por hora, deve ficar em segundo plano (CUKIER, 2014).

Apesar de um expressivo aumento do volume de negócio entre os dois países nos últimos anos, as 
relações comerciais brasileiras com a Índia permanecem pouco intensas. A participação do parceiro asiático na totalidade do comércio exterior brasileiro alcançou apenas $2 \%$ no final da década passada, e ainda assim uma pequena parcela desse volume tem relação com o agronegócio, concentrando-se principalmente em petróleo bruto e minerais.

No tocante ao comércio do Agronegócio, a Índia apresenta-se mais como um concorrente do que parceiro brasileiro. O Brasil disputa com a Índia a liderança mundial nas exportações de carne bovina, posto inclusive que deverá perder esse ano, conforme previsão do Usda (Departamento de Agricultura dos Estados Unidos) (ZAFALON, 2015-A).

Ademais, a Índia possui uma agricultura pouco desenvolvida, de quase subsistência, dependendo da intervenção federal, o que tem gerado atritos com países em desenvolvimento que buscam uma maior liberalização do comércio agrícola (TAVARES, 2014).

\subsection{BRASIL - CHINA}

As relações comerciais sino-brasileiras tiverem um crescimento no período compreendido entre 2000 e 2010 superior a elevação dos índices referente ao comércio entre o Brasil e o mundo, passando de $2 \%$ do total de exportações brasileiras, que totalizavam USD 1,1 bilhão, para USD 30,8 bilhões, o equivalente a $15 \%$ do volume de exportações brasileiras. Crescimento semelhante se deu nas importações chinesas, que avançaram de $2 \%$ - USD 1,2 bilhão - para USD 25,6 bilhões, 14\% do total. A China representa claramente a locomotiva não apenas para o crescimento global, mas também para os demais países do BRICS, conforme se percebe no trecho abaixo destacado:

A respeito do comércio intra-BRICS, verificou-se, a partir dos dados de uma pesquisa, que os fluxos comerciais entre os países-membros são muito reduzidos, com exceção daqueles realizados com a China. Isso parece resultar, por um lado, da concentração das relações comerciais de cada país com países e/ou regiões de sua esfera de preponderância econômica e, por outro lado, do não favorecimento resultante das estruturas das pautas de exportação e importação de cada um deles. (POMERANZ, 2012, p.117).

Apesar de a China ocupar hoje o posto de maior consumidor de grãos do mundo, também se nota que já ocupa a segunda posição como maior produtor de grãos e busca a autossuficiência (TAVARES, 2014). A pauta de exportações chinesas concentra-se em produtos primários e de manufaturas intensivas de recursos naturais, com destaque para a soja e fumo. Essa concentração é bem especificada no trecho colacionado abaixo:

(...) dos últimos 10 anos, para cada dólar que o Brasil adquire de suas exportações para China, 87 centavos vêm de produtos primários e de manufaturas intensivas em recursos naturais, 7 dos produtos de média intensidade tecnológica e apenas 2 centavos das vendas de produtos de alta tecnologia (THORSTENSEN in BRASIL, 2011, p. 17).

O volume de soja consumida pela China é 4,37 vezes superior à sua produção (HIRAKURI; LAZZAROTO, 2011, p. 19). De toda a soja exportada pelo Brasil até outubro de 2013 , cerca de $76 \%$ teve como destino a China. A abertura da economia do país asiático e o grande desenvolvimento da sua economia nos últimos anos tem garantido a demanda aquecida (GARRIDO, 2013). O volume de soja importada pela China nos últimos anos já totaliza USD 87,8 bilhões (MOITINHO, 2015). 
Importante atentar que o risco dessa concentração no comércio de soja pode deixar o país excessivamente exposto aos humores de um único parceiro, e não podemos ignorar que uma desaceleração da economia chinesa, com uma inevitável retração nas compras, vai depreciar os preços internacionais das commodities, afetando a renda dos produtores brasileiros (ZAFALON, 2015-B).

Inegável que no momento existe clara vantagem deste fluxo negocial para nossa economia, mas são necessários investimentos para agregar valor as exportações, ampliando a exportação de óleo e farelo de soja, por exemplo. No tocante ao farelo de soja, a China é o principal consumidor mundial e tem uma taxa anual de crescimento de consumo de 17,23\%. O volume consumido equivale hoje a $99 \%$ de sua produção, ou seja, encontra-se no limite da auto-suficiência (HIRAKURI; LAZZAROTO, 2011).

Situação parecida se apresenta quando analisamos a participação do Brasil nos volumes de óleo de soja exportado. Enquanto a Argentina exporta 68\% de sua produção, o Brasil comercializa externamente somente $17 \%$ da sua, abaixo inclusive da média mundial de 24\%. (HIRAKURI; LAZZAROTO, 2011).

Conforme é explicitado no trecho que vamos colacionar abaixo, o Brasil tem buscado ampliar sua cota de produtos com valor agregado, constatando com o predomínio de grãos in natura:

Às vésperas das reuniões bilaterais com a China e multilaterais com os países do BRICS de julho de 2014, a expectativa era de que o governo brasileiro fizesse exigências contundentes ao governo chinês, a fim de: I) equilibrar os termos de troca, não só favorecendo a entrada de novos produtos agrícolas brasileiros no mercado chinês, mas especialmente de produtos com maior valor agregado; (...) levando a imaginar que o Brasil poderia propor à China acordos comerciais mais interessantes e abrangentes, relacionados não apenas com a expansão do mercado brasileiro de commodities, mas também de produtos manufaturados selecionados e de investimentos. (BECARD; BARROS-PLATIAU; OLIVEIRA, 2015).

Crescente também é o mercado para exportação de proteína animal com esse parceiro. A projeção do consumo de carnes no mercado chinês, no período compreendido entre 1980 e 2020, tem uma previsão de expansão de $52 \%$, superior a expectativa de crescimento no consumo de oleaginosas, com $27 \%$ de projeção (TURRA, 2013).

\subsection{BRASIL - ÁFRICA DO SUL}

Trata-se do país com a menor pauta negocial com o Brasil entre os países integrantes do bloco. O volume de negócios com o Brasil é inferior a $1 \%$ do volume total de comércio exterior, e ao contrário dos demais países integrantes do BRICS é essencialmente composto por produtos industrializados, e nem se percebeu uma ampliação das relações negociais com o Brasil após a formalização do ingresso da África do Sul no BRICS.

Apesar do pequeno volume da balança comercial, é um mercado com grandes oportunidades para o país. África do Sul, conforme estudo de Tavares (2014), é tradicional importadora de produtos agropecuários, em especial de soja e derivados, cujo principal fornecedor atualmente é a Argentina.

Segundo o mesmo estudo, a África do Sul precisa de agricultores e investidores para produzir alimentos e não somente deixar de ser um mercado importador de alimentos, como também exportar para o Oriente Médio e Ásia. 
Mas essa vontade expressa pela África do Sul, de produzir alimentos não surge somente como oportunidade para o mercado brasileiro, mas também como um desafio para a economia brasileira quando se percebe que produtores e investidores chineses já estão aproveitando esta possibilidade.

Mais recentemente, a busca por terras agricultáveis também vem despertando o interesse das nações emergentes, dando origem ao processo de land grabbing. A China é o principal comprador de grandes extensões de terra, visando produzir alimentos para comercialização no território chinês. (...) Nessa corrida pelas terras africanas, novamente as nações emergentes parecem substituir os tradicionais "parceiros" europeus. Dados mostram que a China teria comprado ou alugado pelo menos o dobro de terras que qualquer outra nação. A explicação para isso parece um tanto óbvia: muitas bocas a alimentar e um grande contingente de trabalhadores dispostos a cultivar terras mundo afora. (EMERGÊNCIA DA ÁFRICA, 2012).

Aparentemente o dragão Chinês já percebeu o potencial do Mercado Sul Africano, não somente como consumidor de alimentos, mas também como uma nova fronteira agrícola que está se apresentando para quem primeiro se dispor a explorá-la.

\section{CONSIDERAÇÕES FINAIS}

Com base nos dados apresentados, concluiu-se que são crescentes as oportunidades negociais para o agronegócio brasileiro com a consolidação do bloco BRICS. Apesar de o referido grupo não ter uma organização formal definida, a aproximação decorrente dos encontros de cúpulas anuais e as inúmeras mesas temáticas de discussão favoreceram o incremento da relação bilateral entre os estados membros. Esse incremento é percebido de forma mais clara na relação Brasil - Rússia e, principalmente, na relação Brasil-China. Nota-se que se tratam de países que após as alterações político-econômicas decorrentes da queda do Muro de Berlim ainda não estabeleceram parceiras estratégicas consolidadas.

Da mesma forma que a relação comercial Sino-Brasileira se apresenta como uma grande oportunidade, enxergamos nela também o grande desafio de nossa economia. A crescente centralização de nossa pauta externa com China nos deixa vulnerável a uma retração do crescimento de sua economia, sem contar a ausência de industrialização de nossa pauta negocial. Além disso percebe-se os esforços do Partido Comunista Chinês de ampliar sua participação no mercado agropecuário, inclusive com aquisição de grandes extensões de terras em outros países, como no caso da África do Sul, exposto neste artigo, buscando uma autossuficiência na produção de alimentos.

\section{REFERÊNCIAS}

ABREU, Kátia. Discurso de abertura da $4^{\text {a }}$ Reunião de Ministros de Agricultura e do Desenvolvimento Agrário do BRICS. Brasília, 13 mar. 2015. Disponível em <https://goo.gl/90F8Cz>. Acesso em 27 jun. 2015.

BARBOSA, Rubens. A cúpula do BRIC. Revista de Política Externa, vol. 18 n. 2 set.-out.-nov. 2009. pp. 99-102.

Interesse nacional e visão de futuro. São Paulo: SESI-SP, 2012. 328 p. 
BECARD, Danielly Ramos; BARROS-PLATIAU, Ana Flávia; OLIVEIRA, Carina Costa de. O Brasil, a China e a VI Cúpula do BRICS. Contexto Internacional, Rio de Janeiro, v. 37, n. 1, jun. 2015. p. 81-112. Disponível em <http://goo.gl/2XkRhr>. Acesso em 04 jun. 2015.

BRASIL. Instituto de Pesquisa Econômicas Aplicada. Relações comerciais e de investimentos do Brasil com os demais países do BRICS. Comunicado do IPEA, $\mathrm{n}^{\circ}$ 86, abr. 2011. 50 p. Disponível em <http://goo.gl/RwsuPX>. Acesso em 04 mai. 2015

COZENDEY, Carlos Márcio. BRIC a BRICS em um mundo em transição. In: BRASIL. Ministério das Relações Exteriores. O Brasil, os BRICS e a agenda internacional. Brasília: FUNAG, 2012. pp.107-116.

CUKIER, Heni Ozi. Para que servem os BRICS? Revista Exame: Coluna Risco Político Global, 16 jul. 2014. Disponível em <http://goo.gl/gPtuaP>. Acesso em: 11 mai. 2015.

EMERGÊNCIA da África: o papel da China. AgroAnalysis. Mercado \& negócios. Fev. 2012. Disponível em <http://goo.gl/9Kurz8>. Acesso em: 02 mai. 2015.

FONSECA JÚNIOR, Gélson. BRICS: notas e questões. In: BRASIL. Ministério das Relações Exteriores. O Brasil, os BRICS e a agenda internacional. Brasília: FUNAG, 2012. pp.13-30.

GARRIDO, Marcelo. Soja: análise da conjuntura agropecuário. Paraná: Secretária de Estado da Agricultura e do Abastecimento, nov. 2013. 17 p.

GOLDMAN Sachs. Sobre a Goldman Sachs. Disponível em <http://goo.gl/cl7Tn3>. Acesso em 03 jun. 2015.

HIRAKURI Marcelo Hiroshi; LAZZAROTO, Joelsio José. Evolução e perspectiva de desempenho econômico associados com a produção de soja nos contextos mundial e brasileiro. 3. ed. Londrina: Embrapa Soja, 2011. 69 p.

JONATHAS, Andreh. Brics: quase um bloco? Jornal de Hoje: Fortaleza. 17 jul. 2014. Disponível em <http://goo.gl/HfnCTO>. Acesso em 03 jun. 2015.

KAKHÉLINA, Viktoria. País alcança a sétima posição no mercado mundial de café. Gazeta Russa. 28 nov. 2012. Disponível em < http://goo.gl/kAcicI >. Acesso em: 04 jul. 2015.

LINS E SILVA, Carlos Eduardo. BRICS: De acrônimo esperto a fórum influente. In: BRASIL. Ministério das Relações Exteriores. O Brasil, os BRICS e a agenda internacional. Brasília: FUNAG, 2012. pp. 101-106.

LOSSAN, Aleksêi; SURKOV, Nikolai. Chocolate e flores estarão no foco da retaliação russa. Gazeta Russa. 25 jun. 2015. Disponível em <http://goo.gl/I8O0R1>. Acesso em: 02 jul. 2015.

MOITINHO, Fábio. O dragão tem fome. Dinheiro Rural: Agroeconomia. Ed. 126, ano 10, jun. 2015. Edição digital. 
O’NEILL, Jim. Building better global economic BRICs. Global Economics Paper, Nova York, $\mathrm{n}^{\circ}$ 66, pp. 1-16, nov. 2001.

Globo, 2012. 256 p.

O mapa do crescimento: oportunidades econômicas nos BRICS e além deles. São Paulo:

PERES, Marianna. Novo Embargo Russo. Diário de Cuiabá, ed. 14208, 28 mai. 2015. Disponível em < http://goo.gl/2ttaUV>. Acesso em: 02 jul. 2015.

PFEIZER, Alberto. O Brasil, os BRICS e a agenda internacional. In: BRASIL. Ministério das Relações Exteriores. O Brasil, os BRICS e a agenda internacional. Brasília: FUNAG, 2012. pp.79-86.

POMERANZ, Lenina. O Brasil, os BRICS e a agenda internacional. In: BRASIL. Ministério das Relações Exteriores. O Brasil, os BRICS e a agenda internacional. Brasília: FUNAG, 2012. pp.117-125.

SÁNCHEZ-VALLEJO, Maria Antônia. Tsipras estrecha lazos económicos com Putin em San Petersburgo. El País, Madri. 19 jun. 2015. Disponível em <http://goo.gl/BZU1re>. Acesso em: 24 jun. 2015.

SAMORA, Roberto. Brasil e seu setor de carnes, grandes vencedores do embargo russo aos EUA. Reuters Brasil: Commodities \& Energia. 08 ago. 2014. Disponível em 〈http://goo.gl/qXVbvJ >. Acesso em: 28 jun. 2015.

SANTAYANA, Mauro. O Campo e o BRICS. Jornal do Brasil: Coluna Coisas da Política. 08 ago. 2014. Disponível em <http://goo.gl/j2rLCZ>. Acesso em: 22 abr. 2015.

SILVA. Rodrigo Cássio Marinho da. Os BRICS: considerações sobre os novos atores globais do Século XXI. Revista Acadêmica de Relações Internacionais. vol. 1, n. 3, jul. 2013. pp. 22-36.

SMITH, Erin Cownay. South Africa to be a BRIC. Global Post. 08 jan. 2011. Disponível em <http://goo.gl/MZ1ZQm>. Acesso em: 09 mai. 2015.

SPECTOR, J Brooks. O’Neill: South Africa's inclusion in Brics smacks of politics. Daily Maverick. 04 out. 2011. Disponível em <http://goo.gl/beSLkT>. Acesso em: 15 mai. 2015.

TAVARES, Maria Flávia. Cenário Internacional do Agronegócio. ESPM: Núcleo de Estudos do Agronegócio, jun. 2014.

TURRA, Francisco. Caminhos da soja: conquistas da soja no Brasil. São Paulo: UBABEF, 2013. 30 p.

ZAFALON, Mauro. Produtor rural apoia projeto de terceirização. Folha de São Paulo: Coluna Vaivém das Commodites. 18 abr. 2015. Disponível em <http://goo.gl/QJc0li>. Acesso em: 20 abr. 2015.

Se a China cooperar, agronegócio brasileiro avança na próxima década. Folha de São Paulo: Coluna Vaivém das Commodites. 03 jul. 2015. Disponível em <http://goo.gl/QJc0li>. Acesso em: 
04 jul. 2015.

3. Acrônimo formado pelas iniciais de Brasil, Rússia, Índia, China e África do Sul, em sua grafia em inglês.

4. Banco de investimento, gestão de valores imobiliários e de investimentos fundado em 1869 e sediado em Nova York (GOLDMAN SACHS).

5. N11 (Next Eleven) Coréia do Sul, Indonésia, Irã ${ }_{s}$ México, Turquia, Filipinas, Egito, Nigéria, Paquistão, Vietnã e Bangladesh (O’NEILL, 2012).

6. Embargo prorrogado pelo período de mais um ano em 24 jun. 2015 (LOSSAN; SURKOV, 2015).

[1] Bacharel em Ciências Jurídicas e Sociais pela Universidade do Vale do Rio dos Sinos - UNISINOS. Especialista em Direito Empresarial pela mesma Instituição de ensino. Pós-Graduando em MBA em Agronegócios pelo Cento Universitário Cesumar - UniCesumar.

[2] Doutora em Educação e Currículo pela Pontifícia Universidade Católica de São Paulo, é Mestre em Educação pela PUCPR. Especialista em Gestão da Informação pela Fundação de Estudos Sociais do Paraná e em Educação a Distância pela Faculdade Educacional da Lapa. É graduada em Biblioteconomia pela Universidade Federal do Paraná e em Pedagogia pela Universidade Castelo Branco.

\section{PUBLIQUE SEU ARTIGO CIENTÍFICO EM:}

https://www.nucleodoconhecimento.com.br/enviar-artigo-cientifico-para-submissao 